\title{
The validity of health-related quality of life questionnaires in bronchiectasis: a systematic review and meta-analysis
}

\author{
Arietta Spinou, ${ }^{1}$ Konstantinos C Fragkos, ${ }^{2}$ Kai K Lee, ${ }^{3}$ Caroline Elston, ${ }^{3}$ \\ Richard J Siegert, ${ }^{4}$ Michael R Loebinger, ${ }^{5}$ Robert Wilson, ${ }^{5}$ Rachel Garrod, ${ }^{6}$ \\ Surinder S Birring ${ }^{1}$
}

\begin{abstract}
- Additional material is published online only. To view please visit the journal online (http://dx.doi.org/10.1136/ thoraxjnl-2015-207315)
\end{abstract}

For numbered affiliations see end of article.

\section{Correspondence to} Dr Surinder S Birring, Division of Asthma, Allergy and Lung Biology, King's College London, Denmark Hill, London SE9 5RS, UK; surinder.birring@ nhs.net

Received 26 May 2015 Revised 18 October 2015 Accepted 3 November 2015 Published Online First 11 February 2016

\section{SLinked}

- http://dx.doi.org/10.1136/ thoraxjnl-2015-207473

CrossMark

To cite: Spinou $A$ Fragkos KC, Lee KK, et al. Thorax 2016;71:683-694.

\section{ABSTRACT}

Background $A$ range of questionnaires have been used to assess health-related quality of life (HRQOL) in bronchiectasis. A systematic review was conducted to evaluate their psychometric properties and assess associations between HRQOL and clinical measures. Methods Five electronic databases were searched. Studies eligible for inclusion were those that investigated the validity of HRQOL questionnaires and/or their association with other outcomes in adults with bronchiectasis. Patients with cystic fibrosis were excluded. The identified questionnaires were assessed for convergent, discriminant and cross-cultural translation validity; missing data, floor and ceiling effects, internal consistency, responsiveness and test-retest reliability. A meta-analysis was conducted to estimate the strength of associations between HRQOL and clinical measures.

Results From 1918 studies identified, 43 studies were included in the systematic review, of which 38 were suitable for the meta-analysis. Nine HRQOL

questionnaires were identified, with the most widely used being: St George's Respiratory Questionnaire, Leicester Cough Questionnaire, Quality of Life-Bronchiectasis and Short Form-36. HRQOL questionnaires had moderate to good internal consistency and good test-retest reliability. Only 8 of 18 studies that used translated HRQOL questionnaires reported or referred to the validity of the translated questionnaire. There was a stronger correlation (mean $\mathrm{r}(95 \% \mathrm{CI})$ ) between HRQOL and subjective outcome measures, such as dyspnoea 0.55 (0.41 to $0.68)$ ) and fatigue (0.42 (0.23 to 0.58)) compared with objective measures; exercise capacity $(-0.41(-0.54$ to $-0.24)), \mathrm{FEV}_{1} \%$ predicted $(-0.31$ ( -0.40 to -0.23$)$ ) and extent of bronchiectasis on CT scan 0.35 (0.03 to $0.61)$ ); all $p<0.001$.

Conclusions This review supports most HRQOL questionnaires used in bronchiectasis have good psychometric properties. There was a weak to moderate association between HRQOL and objective outcome measures. This suggests that HRQOL questionnaires assess a unique aspect of health not captured by objective measures.

\section{INTRODUCTION}

The assessment of health-related quality of life (HRQOL) is important in chronic disease as it evaluates the overall impact on health from the

\section{Key messages}

What is the key question?

- Which health-related quality of life questionnaires are used in bronchiectasis and what is the evidence for their validity?

What is the bottom line?

- Despite differences in the construct of frequently used questionnaires St George's Respiratory Questionnaire, Leicester Cough Questionnaire and Quality of LifeBronchiectasis, there is good evidence to support their validity, internal reliability and repeatability.

\section{Why read on?}

- This article provides an in-depth review of the evidence for the validity of health-related quality of life questionnaires and their association with commonly used clinical outcome parameters; this may help investigators select the most appropriate tool for their purpose.

patient's perspective. HRQOL is defined as 'the perception of the impact of health on an individual's contentment or satisfaction with life in areas they consider important'. ${ }^{1}$ Bronchiectasis is a persistent or progressive condition characterised by dilated thick-walled bronchi. ${ }^{2}$ Symptoms of bronchiectasis include sputum production, cough, haemoptysis, dyspnoea and fatigue, which are worse during exacerbations. HRQOL is impaired in bronchiectasis. ${ }^{3}$ A range of tools have been used to assess HRQOL in bronchiectasis. These include generic tools such as the Medical Outcomes Study 36-Short Form Health Survey (SF-36), organspecific tools such as the St George's Respiratory Questionnaire (SGRQ) and Leicester Cough Questionnaire (LCQ) and the condition-specific Quality of Life-Bronchiectasis (QOL-B). ${ }^{4-7}$ The comparative validity of HRQOL questionnaires used to assess bronchiectasis has not been investigated; such a review may inform investigators and clinicians about the choice of HRQOL questionnaires available and their validity. The aim of this 
systematic literature review was to evaluate the psychometric properties of questionnaires used to assess HRQOL in bronchiectasis. This included a meta-analysis to assess the associations of HRQOL with other clinical measures.

\section{METHODS}

\section{Study eligibility criteria}

The inclusion criteria were: empirical studies of adult patients ( $\geq 18$ years old) with bronchiectasis, studies reporting the psychometric properties of generic and disease-specific HRQOL questionnaires, and/or the association of HRQOL with other clinical measures. The diagnosis of bronchiectasis was established using clinical and/or radiological features. The review was limited to studies reporting in English language. Studies investigating acute exacerbations were included if they met the inclusion criteria. Studies investigating mixed populations such as adult/paediatric and non-cystic fibrosis/cystic fibrosis bronchiectasis were included if the findings reported were distinguishable by age/disease category. The exclusion criteria were: diagnosis of cystic fibrosis and review articles (used only to identify further references). Studies using cognitive interview or focus group methodology that did not include HRQOL questionnaires were also excluded.

The psychometric properties considered included convergent and discriminant validity (relationship with other clinical measures according to expectations), internal consistency (Cronbach's $\alpha$ coefficient: extent to which the items of a questionnaire are inter-related), test-retest reliability (repeatability during a clinically stable period), responsiveness (response to change using standardised response mean, SRM), missing data, floor (minimum score) and ceiling (maximum score) effects. The validity of translated HRQOL questionnaires was evaluated by assessing if forward/backward translation, cognitive interviews, internal consistency and reliability were reported.

\section{Search strategy and terms}

Preferred Reporting Items for Systematic Reviews and MetaAnalyses (PRISMA) guidelines and Scottish Intercollegiate Guidelines Network (SIGN) methodology checklist for systematic reviews and meta-analyses were used. ${ }^{8} 9$ The search was conducted in five electronic databases: Embase (1974-2014), Pubmed, Medline (Ovid, 1946-2014), PsycINFO (1806-2014) and Cochrane Library. The keywords for search were: non cystic fibrosis bronchiectasis/bronchiectasis, quality of life/QOL/ HRQOL, health status, well-being, daily living, questionnaire, validation/validity, psychology and psychometrics. The search was repeated with additional keywords that included named HRQOL questionnaires identified in the previous search. The date of search was 6 November 2014. The references from all included manuscripts were used to identify further studies. Abstracts with adequate information about study methods and results were considered for inclusion.

\section{Study selection, data extraction and quality assessment}

After duplicate references were removed, two reviewers independently assessed the studies (in abstract form) against the inclusion criteria. When there was insufficient information available in the abstract, the full text was reviewed. Discrepancies between the reviewers were resolved through discussion and consensus. Two investigators then extracted data from the selected studies including: author, year of publication, aim of the study, sample size, most common aetiology of bronchiectasis, age, gender, $\mathrm{FEV}_{1} \%$ predicted, HRQOL questionnaire used and psychometric properties of HRQOL questionnaire including correlation of HRQOL with other clinical measures. Clinical measures used for convergent and discriminant validity of HRQOL included those that assessed symptoms, anxiety, depression, exercise capacity, lung function and other physiological parameters and markers of disease severity and infection/exacerbation. The quality of studies was assessed using a critical appraisal tool developed by Swigris et $a l^{1}$ and modified for bronchiectasis (see online supplementary appendix 1 ). Where translated questionnaires were used, the translation procedure was assessed by evaluating the included study and related references for forward-backward translation, cognitive interviews, floor and ceiling effects, internal consistency and test-retest reliability.

The minimal clinically important difference (MCID), the smallest change in an HRQOL questionnaire score that is deemed important by patients, was identified if available for patients with bronchiectasis. Studies reporting MCID for questionnaires in other chronic respiratory disorders were presented if data was unavailable for bronchiectasis, following an additional literature search. Responsiveness of the included questionnaires was assessed from randomised-controlled trials returned in our search, by calculating the SRM when possible for the total sample population, and treatment and placebo groups individually. Clinical trials were otherwise excluded from the systematic review unless the primary purpose was to study the psychometric properties of HRQOL questionnaires.

\section{Statistical analysis}

Quantitative analysis was performed with Stata V.12.0 (StataCorp LP, Texas, USA) and MetaWin V.2.0 (Baker Hughes, Houston). Internal consistency was reported as Cronbach's $\alpha$ coefficient (acceptable if $>0.7$ ) and test-retest reliability as intraclass correlation coefficient (ICC) (moderate if $=0.5-0.7$ and good if >0.7). Meta-analysis was performed to evaluate the association between HRQOL and clinical measures when data was available from at least two studies. When multiple questionnaires were used to assess HRQOL in the same study, the most relevant questionnaire to bronchiectasis was used in the meta-analysis. When the total score was not available, the mean of the domain scores was used. When the data were repeated in multiple publications, the meta-analysis included the publication with the largest sample size that best met the inclusion criteria.

Correlation coefficients were extracted from the studies when available. The strength of association was categorised as following: weak $r<0.4$, moderate $r=0.4-0.7$ and strong $r>0.7$; significance $p<0.05$. When only $p$ values and other metrics ( $t$ values, Cohen's d, F values, $\chi^{2}$ values) were available, correlation coefficients were obtained according to formulas suggested by Rosenthal et al. ${ }^{10} \mathrm{~A}$ detailed description of correlation coefficients and Fisher's Z calculations is given in online supplementary appendix 2. SRMs were calculated when data was available from mean difference in HRQOL scores (pre/post intervention)/ SD of the difference (trivial effect $<0.20$, small effect $=0.20$ 0.50 , moderate effect $=0.50-0.80$ and large effect $>0.80$ ). Standard formulae for computing SD were used when values were not directly available. ${ }^{11}$ Publication bias was assessed using funnel plots and Rosenthal's fail-safe number (Rosenthal's N), ${ }^{12}$ online supplementary appendix 2 .

\section{RESULTS}

\section{Study characteristics}

Study selection

The search retrieved 1918 publications (see online supplementary table E1). Two additional abstracts and a full manuscript were added manually from searching references. ${ }^{13-15}$ A PRISMA flow chart illustrates the studies selection process and 


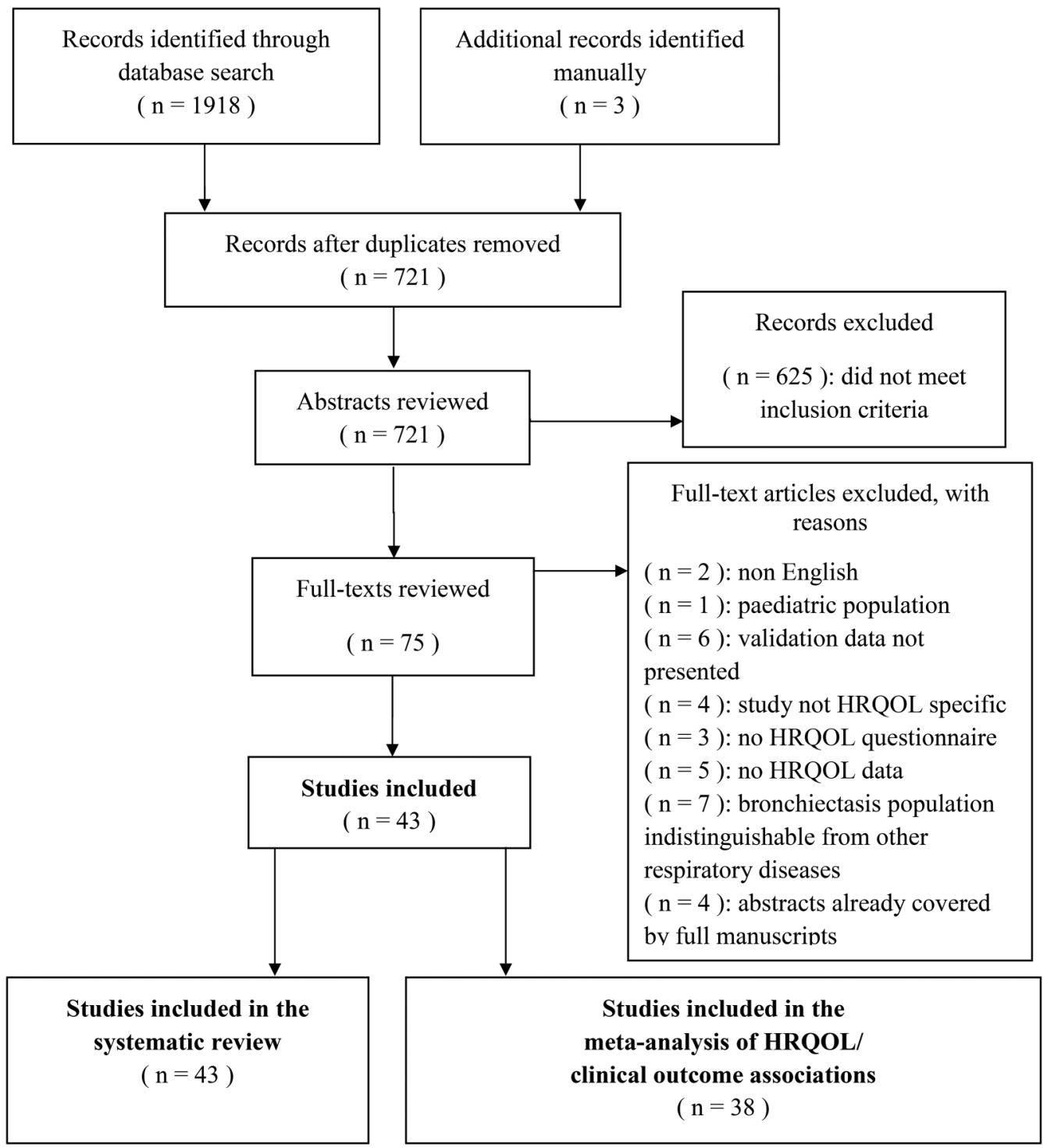

Figure 1 PRISMA flow chart of the literature review and meta-analysis selection process. HRQOL, health-related quality of life.

reasons for exclusion (figure 1). Forty-three studies met the inclusion criteria for systematic review, of which 38 were included in the meta-analysis of associations between HRQOL and other clinical measures. Studies with multiple publications were combined and considered as single publications. Five studies had subjects who overlapped with those in other publications (table 1).

Overview of included studies and study quality

The objectives of the included studies are presented in table 1. All studies were prospective. They all reported cross-sectional findings apart from one, ${ }^{16}$ while nine studies also included longitudinal findings for the investigation of repeatability of the HRQOL questionnaires. ${ }^{5-7} 141^{17-21}$ Nine studies were published in abstract form (indicated in reference list and online supplementary material). The studies met a mean (SD) of 48 (14) \% of the quality criteria; range $17-78 \%$ (figure 2 ). No study met the criteria for all quality domains.

\section{Characteristics of patients}

Table 1 presents the clinical characteristics of patients. The studies included a total number of 3727 patients with bronchiectasis (median number of patients with bronchiectasis per study 98, range 6-608). The mean study patient age was 59 (range 43-70) years and 64 (range 37-83) \% of the patients were female. Three studies also recruited participants during an exacerbation, ${ }^{22-24}$ while all remaining studies recruited patients during a clinically stable phase. Eight studies did not report CT scan findings. 131422 25-29

\section{HRQOL questionnaires}

Overview of HRQOL questionnaires

Seven organ/disease-specific and two generic HRQOL questionnaires were identified in the selected studies (table 1). Fifteen studies administered multiple HRQOL questionnaires. Twenty-seven studies used the SGRQ, nine the LCQ, eight the SF-36, six the QOL-B V. 2.0 or V.3.0, two the Chronic Respiratory Disease Questionnaire, two the generic Euro Quality of Life and one each of the COPD assessment tool (CAT), the 20-Item Sinonasal Outcome Test and the Cough Quality of Life Questionnaire. A description of these HRQOL questionnaires is given in online supplementary appendix 3, including their length, administration and scoring. All questionnaires were originally developed in English. A summary of 


\begin{tabular}{|c|c|c|c|c|c|c|c|c|c|}
\hline Author 1st, year & HRQOL tools & Country & $\mathrm{N}$ & $\begin{array}{l}\text { Age } \\
\text { (year) }\end{array}$ & $\begin{array}{l}\text { Female } \\
(\%)\end{array}$ & $\begin{array}{l}\mathrm{FEV}_{1} \% \\
\text { (pred) }\end{array}$ & $\begin{array}{l}\text { Most common } \\
\text { bronchiectasis } \\
\text { aetiology }\end{array}$ & $(\%)$ & Relevant study objectives \\
\hline Wilson, 1997a, O'Leary, 2002 & SGRQ, SF-36 & UK & 111 & 52 & 60 & 66.4 & Idiopathic & 58 & $\begin{array}{l}\text { Validate SGRQ in bronchiectasis } \\
\text { Relationship between HRQOL, anxiety and depression }\end{array}$ \\
\hline Wilson, 1997b, Wilson, 1998 & SGRQ, SF-36 & UK & 87 & 54 & 56 & 63.8 & Idiopathic & 63 & $\begin{array}{l}\text { Relationship between HRQOL, sputum bacteriology and systemic } \\
\text { inflammatory markers }\end{array}$ \\
\hline Chan, 2002 & SGRQ, SF-36 & HK & 93 & 59 & 66 & 73.5 & Idiopathic & 81 & Validate Hong Kong Chinese version of SGRQ \\
\hline Martinez-Garcia, 2005a, 2005b & SGRQ & ES & 102 & 70 & 37 & 60.4 & Idiopathic & 44 & $\begin{array}{l}\text { Validate SGRQ in bronchiectasis } \\
\text { Relationship between HRQOL and clinical outcomes }\end{array}$ \\
\hline Eshed, 2007 & SGRQ & IL & 46 & 63 & 54 & 72.3 & NR & & Relationship between SGRQ and CT scores \\
\hline Tomkinson, 2009 & SGRQ & UK & 6 & $59^{*}$ & 83 & $50.5^{*}$ & NR & & Relationship between HRQOL and exercise capacity \\
\hline Guilemany, 2009 & $\begin{array}{l}\text { SGRQ, SF-36, } \\
\text { SNOT-20 }\end{array}$ & ES & 80 & 57 & 71 & 80.8 & NR & & Relationship between HRQOL and chronic rhinosinusitis \\
\hline Lee, 2009 & SGRQ, SF-36 & AU & 27 & 54 & 59 & 73.9 & Postinfective & 47 & Relationship between HRQOL and exercise capacity \\
\hline Shoemark, 2011 & SGRQ & UK & 53 & 57 & 71 & $82.1^{*}$ & NR & & Relationship between HRQOL and exhaled nitric oxide \\
\hline Gale, 2010 & SGRQ & UK & 20 & $65^{*}$ & 80 & 67.8 & NR & & $\begin{array}{l}\text { Relationship between HRQOL, fatigue, balance and self-reported physical } \\
\text { activity }\end{array}$ \\
\hline Batchelor, 2011 & SGRQ & UK & 31 & 59 & 81 & NR & Postinfective & 48 & $\begin{array}{l}\text { Relationship between HRQOL, exacerbation frequency, depression, fatigue } \\
\text { and lung function }\end{array}$ \\
\hline Chalmers, 2014 & SGRQ & UK, BE, IT & 608 & 65 & 60 & 69.3 & $\begin{array}{l}\text { Idiopathic and } \\
\text { Postinfective }\end{array}$ & 63 & Relationship between HRQOL and Bronchiectasis Severity Index \\
\hline Galindo, 2013 & SGRQ & $\mathrm{MX}$ & 19 & NR & 74 & NR & CVID & 100 & Relationship between HRQOL and sex \\
\hline Oliveira, 2014a, 2014b & QOL-B (V3.0), SGRQ & ES & 207 & 57 & 63 & 68.3 & Postinfective & 39 & $\begin{array}{l}\text { Validate QOL-B (V3.0) in Spanish } \\
\text { Relationship between HRQOL, anxiety and depression }\end{array}$ \\
\hline Loebinger, 2009 & SGRQ & UK & 91 & 52 & 58 & 65.8 & Idiopathic & 56 & Relationship between HRQOL and mortality risk \\
\hline Lee, 2012 & CAT, SGRQ & KR & 62 & 61 & 53 & 67.3 & NR & & Validate the Korean CAT in bronchiectasis \\
\hline Moreno, 2013 & SGRQ & ES & 70 & 64 & 69 & 74.0 & Idiopathic & 46 & Relationship between HRQOL, anxiety and depression \\
\hline Rowan, 2014 & SGRQ & UK & 60 & 62 & 70 & 76.5 & Idiopathic & 43 & Relationship between HRQOL and lung clearance index \\
\hline Gao, 2014 & SGRQ & $\mathrm{CN}$ & 144 & 46 & 62 & 67.4 & $\begin{array}{l}\text { Idiopathic and } \\
\text { Postinfective }\end{array}$ & 71 & Relationship between HRQOL and quality of sleep \\
\hline Morsi, 2014 & SGRQ & EG & 33 & 43 & 55 & 32.9 & NR & & $\begin{array}{l}\text { Relationship between HRQOL, anxiety and depression and other clinical } \\
\text { measures }\end{array}$ \\
\hline Murray, 2009b & SGRQ & UK & 32 & 69 & 63 & 66.5 & ABPA & 34 & Investigate the HRQOL as an end-point for assessing treatment \\
\hline Guilemany, 2006 & SF-36 & ES & 60 & 52 & 65 & 81.0 & NR & & Relationship between HRQOL, nasal symptoms and polyposis \\
\hline Jacques, 2012 & SF-36 & BR & 70 & 55 & 69 & 44.9 & Idiopathic & 46 & Relationship between HRQOL and exercise capacity \\
\hline Polley, 2008 & $\begin{array}{l}\text { LCQ, CQLQ, } \\
\text { EuroQOL }\end{array}$ & UK & 26 & 58 & 50 & 73.2 & NR & & Relationship among different HRQOL questionnaires \\
\hline Ozalp, 2012 & LCQ & TR & 20 & 44 & 50 & 62.5 & NR & & Relationship between HRQOL and dyspnoea, exercise capacity, fatigue \\
\hline Murray, 2009a, 2009c & LCQ, SGRQ & UK & 141 & 68 & 64 & 74.0 & Postinfective & 53 & $\begin{array}{l}\text { Relationship between HRQOL and sputum colour } \\
\text { Validate the LCQ in bronchiectasis }\end{array}$ \\
\hline Munoz, 2013 & LCQ, SGRQ & ES & 259 & 58 & NR & NR & NR & & Validate LCQ Spanish version in bronchiectasis \\
\hline Altenburg, 2014 & LCQ, SGRQ, SF-36 & NL & 60 & 67 & 58 & 82.3 & Idiopathic & 50 & $\begin{array}{l}\text { Relationship between HRQOL and lower respiratory tract infections visual } \\
\text { analogue score }\end{array}$ \\
\hline Goeminne, 2014 & LCQ & BE & 63 & 59 & 57 & 69.0 & Idiopathic & 27 & Relationship between HRQOL, lung function and inflammatory markers \\
\hline Torrego, 2006 & LCQ & UK & 22 & 59 & 82 & 82.9 & NR & & Relationship between HRQOL and cough reflex \\
\hline
\end{tabular}




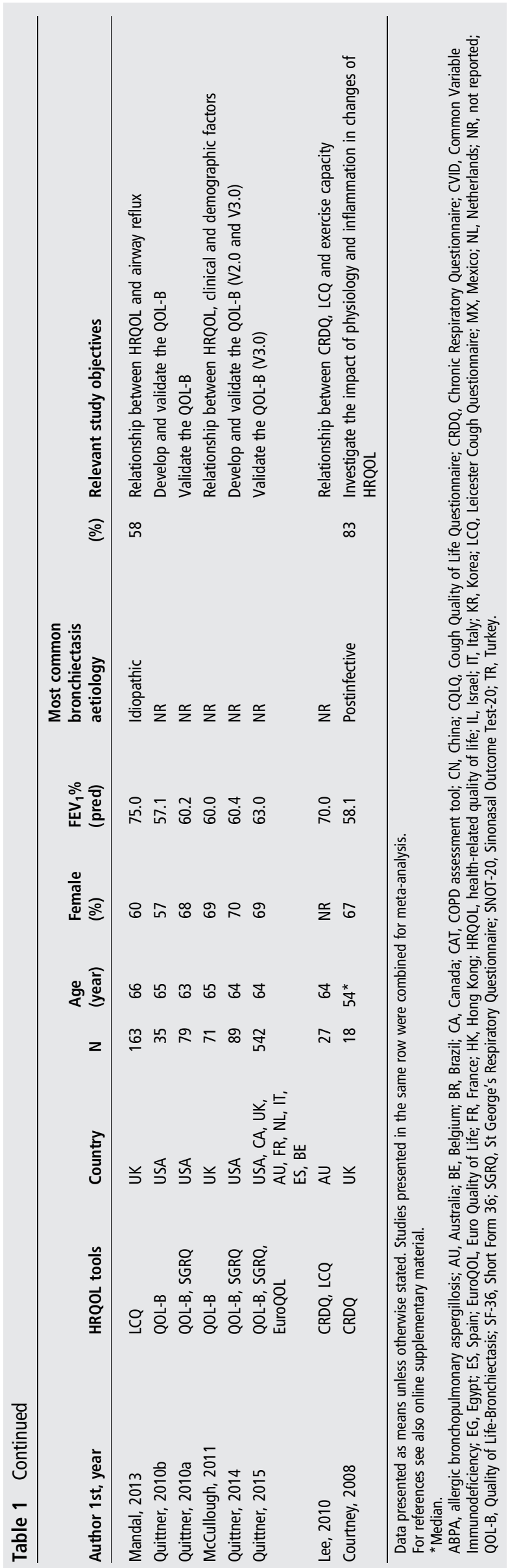

average HRQOL scores from studies, where available, is presented in online supplementary table E2.

\section{Validity of translated questionnaires}

Eighteen studies used a translated HRQOL questionnaire and only eight reported or referenced a validation of the translated questionnaire (see online supplementary appendix 4).

\section{Floor/ceiling effects and missing data}

Floor and ceiling effects and missing data were reported for only two HRQOL questionnaires, SGRQ and QOL-B and were relatively small for most total and domain scores (see online supplementary appendix 5).

Internal consistency

Cronbach's $\alpha$ coefficients for the HRQOL questionnaires ranged from moderate to high (table 2). The LCQ had the highest internal consistency (Cronbach's $\alpha$ coefficient 0.910.94). ${ }^{14}$ QOL-B Cronbach's $\alpha$ coefficients ranged from 0.65 to $0.96,{ }^{6} 2021$ SGRQ from 0.59 to $0.92,{ }^{5} 1730$ SF-36 from 0.75 to $0.91^{31}$ and for CAT it was $0.84 .^{32}$ The internal consistency of other questionnaires was not reported.

Test-retest reliability

Test-retest reliability data were available for SGRQ, QOL-B and LCQ. ICC was moderate to high (table 2). The SGRQ was slightly more repeatable over 2 weeks than the QOL-B (ICC range $0.89-0.97$ vs $0.67-0.88$, respectively). 5617202133 The LCQ was highly repeatable over 6 months $(\mathrm{ICC}=0.96){ }^{7}$

\section{MCID and responsiveness}

MCID in bronchiectasis was reported only for the QOL-B questionnaire, range 7-10 units. ${ }^{21} 33$ MCID for HRQOL questionnaires in other chronic respiratory diseases is presented in online supplementary table E3. Twenty randomised-controlled trials included sufficient data to assess responsiveness; there was a wide range of SRMs from trivial to large (see online supplementary table E4).

\section{Discriminant ability of HRQOL questionnaires}

SGRQ was able to discriminate between subjects based on the severity of dyspnoea ${ }^{50}$ and wheeze, ${ }^{5}$ sputum volume, ${ }^{17}{ }^{30} \mathrm{CT}$ scan extent of bronchiectasis, ${ }^{34}$ exacerbation frequency, ${ }^{5} 3035$ sputum colonisation by Pseudomonas aeruginosa, ${ }^{30}$ history of haemoptysis in the past year ${ }^{21}$ and the bronchiectasis severity index. ${ }^{35}$ SGRQ total scores were able to discriminate $\mathrm{FEV}_{1} \%$ categories. $^{30}$ There were conflicting data for the discriminative ability of the QOL-B based on $\mathrm{FEV}_{1} \%$. The number of QOL-B domains reported in studies as able to discriminate patients on the basis of $\mathrm{FEV}_{1} \%$ ranged from one to all eight domains. ${ }^{6} 2133$ QOL-B was however able to discriminate between patients according to CT scan extent of bronchiectasis and sputum Pseudomonas aeruginosa and Haemophilus influenza colonisation. $^{21}$

\section{Associations between HRQOL and clinical measures: a meta-analysis}

The associations between HRQOL and other clinical measures (convergent/discriminant validity) reported in studies were evaluated in a meta-analysis (table 3). The associations for clinical measures where only single studies were available are presented in online supplementary table E5. A wide range of associations between HRQOL and clinical measures were reported (see figures 3-6 and online supplementary figures E1-E14). The 


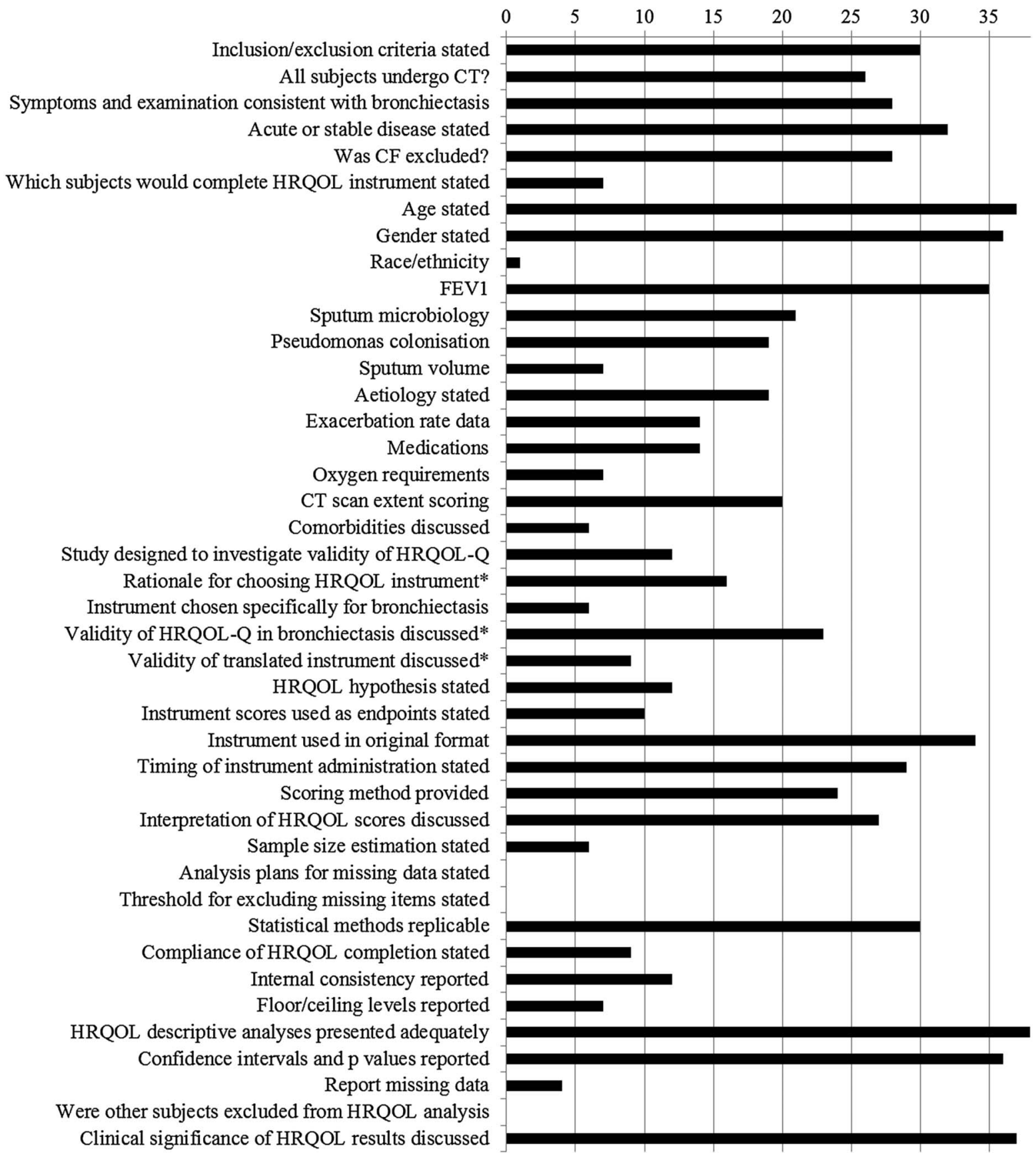

Figure 2 Estimated quality of reporting for included studies. $x$ axis: number of studies meeting each quality criterion (total $n=43$ ), $y$ axis: quality criterion item. Number of total evaluable studies 43 except where indicated as*. CF, cystic fibrosis; CT, computed tomography; HRQOL, healthrelated quality of life; HRQOL-Q, health-related quality of life questionnaire.

strongest associations of HRQOL were with dyspnoea (figure 3) and fatigue (see online supplementary figure E2) and for objective measures with exercise capacity (figure 4), where there were moderate correlations. The association with cough was $r=0.56$ with a $\mathrm{p}$ value approaching significance $(\mathrm{p}=0.06$, only two studies), figure 5. There was a weak association between HRQOL and sputum volume (see online supplementary figure E4) and microbiological colonisation (see online supplementary figure E13), lung function (see figure 6 and online supplementary figure E11), exacerbation rate (see online supplementary figure E10) and extent of bronchiectasis on CT scans (see online supplementary figure E6). The association between HRQOL questionnaires ranged from weak to strong (see online supplementary appendix 6).
Analysis of publication bias and heterogeneity

Publication bias was assessed with a funnel plot for $\mathrm{FEV}_{1} \%$ predicted and exercise capacity, as these were parameters with $>10$ studies available (see online supplementary figures E15 and E16). $\mathrm{FEV}_{1} \%$ resembled a symmetric image, suggesting no publication bias. Exercise capacity funnel had slight asymmetry suggesting possibility of publication bias. However, this was not confirmed with Enger's test $(p=0.189)$.

\section{DISCUSSION}

This is the first systematic review of the psychometric properties of HRQOL questionnaires used to assess bronchiectasis. The review included 43 studies that investigated 3727 patients 
Table 2 Internal consistency and test-retest reliability of HRQOL questionnaires in non-cystic fibrosis bronchiectasis

\begin{tabular}{|c|c|c|c|c|c|}
\hline \multirow[b]{2}{*}{ Author 1st, year } & \multirow[b]{2}{*}{ HRQOL questionnaire } & \multicolumn{2}{|l|}{ Internal consistency } & \multicolumn{2}{|l|}{ Test-retest reliability } \\
\hline & & Domain & Cronbach's $\boldsymbol{\alpha}$ & Domain & ICC \\
\hline Wilson, 1997 & SGRQ & $\begin{array}{l}\text { Total } \\
\text { Symptoms } \\
\text { Activity } \\
\text { Impact }\end{array}$ & $\begin{array}{l}\text { NR } \\
0.90 \\
0.89 \\
0.92\end{array}$ & $\begin{array}{l}\text { Total } \\
\text { Symptoms } \\
\text { Activity } \\
\text { Impact }\end{array}$ & $\begin{array}{l}0.97 \\
0.93 \\
0.98 \\
0.94\end{array}$ \\
\hline Martinez-Garcia, 2005 & SGRQ & $\begin{array}{l}\text { Total } \\
\text { Symptoms } \\
\text { Activity } \\
\text { Impact }\end{array}$ & $\begin{array}{l}0.90 \\
0.81 \\
0.87 \\
0.81\end{array}$ & $\begin{array}{l}\text { Total } \\
\text { Symptoms } \\
\text { Activity } \\
\text { Impact }\end{array}$ & $\begin{array}{l}N R \\
N R \\
N R \\
N R\end{array}$ \\
\hline Chan, 2002 & SGRQ & $\begin{array}{l}\text { Total } \\
\text { Symptoms } \\
\text { Activity } \\
\text { Impact }\end{array}$ & $\begin{array}{l}0.92 \\
0.59 \\
0.91 \\
0.88\end{array}$ & $\begin{array}{l}\text { Total } \\
\text { Symptoms } \\
\text { Activity } \\
\text { Impact }\end{array}$ & $\begin{array}{l}0.93 \\
0.94 \\
0.84 \\
0.89\end{array}$ \\
\hline Quittner, 2010b & QOL-B & 8 domains & (range) $0.65-0.94$ & 8 domains & (range) $0.72-0.88$ \\
\hline Quittner, 2010a & QOL-B & 8 domains & (range) $0.73-0.96$ & 8 domains & NR \\
\hline Quittner, 2014 & QOL-B V3.0* & $\begin{array}{l}\text { Physical functioning } \\
\text { Role functioning } \\
\text { Vitality } \\
\text { Emotional functioning } \\
\text { Social functioning } \\
\text { Treatment burden } \\
\text { Health perceptions } \\
\text { Respiratory symptoms }\end{array}$ & $\begin{array}{l}0.94 \\
0.86 \\
0.85 \\
0.72 \\
0.66 \\
0.84 \\
0.77 \\
0.82\end{array}$ & $\begin{array}{l}\text { Physical functioning } \\
\text { Role functioning } \\
\text { Vitality } \\
\text { Emotional functioning } \\
\text { Social functioning } \\
\text { Treatment burden } \\
\text { Health perceptions } \\
\text { Respiratory symptoms }\end{array}$ & $\begin{array}{l}0.88 \\
0.84 \\
0.67 \\
0.82 \\
0.85 \\
0.76 \\
0.78 \\
0.80\end{array}$ \\
\hline Quittner, 2015 & QOL-B V3.0 & $\begin{array}{l}\text { Physical functioning } \\
\text { Role functioning } \\
\text { Vitality } \\
\text { Emotional functioning } \\
\text { Social functioning } \\
\text { Treatment burden } \\
\text { Health perceptions } \\
\text { Respiratory symptoms }\end{array}$ & $\begin{array}{l}0.91 \\
0.84 \\
0.73 \\
0.83 \\
0.77 \\
0.78 \\
0.77 \\
0.81\end{array}$ & $\begin{array}{l}\text { Physical functioning } \\
\text { Role functioning } \\
\text { Vitality } \\
\text { Emotional functioning } \\
\text { Social functioning } \\
\text { Treatment burden } \\
\text { Health perceptions } \\
\text { Respiratory symptoms }\end{array}$ & $\begin{array}{l}0.85 \\
0.86 \\
0.74 \\
0.79 \\
0.80 \\
0.76 \\
0.76 \\
0.83\end{array}$ \\
\hline Olveira, 2014 & QOL-B V3.0 & $\begin{array}{l}\text { Physical functioning } \\
\text { Role functioning } \\
\text { Vitality } \\
\text { Emotional functioning } \\
\text { Social functioning } \\
\text { Treatment burden } \\
\text { Health perceptions } \\
\text { Respiratory symptoms }\end{array}$ & $\begin{array}{l}0.91 \\
0.84 \\
0.82 \\
0.84 \\
0.70 \\
0.72 \\
0.71 \\
0.87\end{array}$ & $\begin{array}{l}\text { Physical functioning } \\
\text { Role functioning } \\
\text { Vitality } \\
\text { Emotional functioning } \\
\text { Social functioning } \\
\text { Treatment burden } \\
\text { Health perceptions } \\
\text { Respiratory symptoms }\end{array}$ & $\begin{array}{l}0.88 \\
0.86 \\
0.78 \\
0.86 \\
0.78 \\
0.68 \\
0.83 \\
0.83\end{array}$ \\
\hline Murray, 2009 & $\mathrm{LCQ}$ & $\begin{array}{l}\text { Total } \\
\text { Physical } \\
\text { Psychological } \\
\text { Social }\end{array}$ & $\begin{array}{l}\text { NR } \\
\text { NR } \\
\text { NR } \\
\text { NR }\end{array}$ & $\begin{array}{l}\text { Total } \\
\text { Physical } \\
\text { Psychological } \\
\text { Social }\end{array}$ & $\begin{array}{l}0.96 \\
N R \\
N R \\
N R\end{array}$ \\
\hline Munoz, 2013 & LCQ & $\begin{array}{l}\text { Total } \\
\text { Physical } \\
\text { Psychological } \\
\text { Social }\end{array}$ & $\begin{array}{l}0.91 \\
0.94 \\
0.93 \\
0.93\end{array}$ & $\begin{array}{l}\text { Total } \\
\text { Physical } \\
\text { Psychological } \\
\text { Social }\end{array}$ & $\begin{array}{l}N R \\
N R \\
N R \\
N R\end{array}$ \\
\hline Lee, 2012 & CAT & Total & 0.84 & Total & NR \\
\hline Guilemany, 2006 & SF-36 & 8 domains & (range) $0.75-0.91$ & & NR \\
\hline
\end{tabular}

${ }^{*}$ The repeatability of QOL-B V.3.0 was not reported. Table presents data from QOL-B V.2.0. ${ }^{6}$

Cronbach's $\alpha$ coefficient $>0.7$ is considered acceptable for HRQOL questionnaires.

For references see also online supplementary material.

CAT, COPD assessment tool; HRQOL, health-related quality of life; ICC, intraclass correlation coefficient; LCQ, Leicester Cough Questionnaire; NR, not reported; QOL-B, Quality of Life-Bronchiectasis; SF-36, Short Form 36; SGRQ, St George's Respiratory Questionnaire.

and identified nine HRQOL questionnaires. For the assessment of the questionnaires, we used criteria recommended by the Food and Drug Administration guidelines. ${ }^{36}$ Our systematic review suggests that the identified questionnaires have generally good internal consistency, test-retest reliability and convergent validity. The SGRQ was the most widely studied questionnaire. This questionnaire was initially developed for COPD and asthma, but has subsequently been validated and used in a wide range of respiratory disorders. The next most commonly used tool was the LCQ, which was initially developed for patients with chronic cough, but has been validated in patients with bronchiectasis. The QOL-B, a recently published questionnaire, was the only questionnaire developed specifically for bronchiectasis.

We identified some relatively small differences in the psychometric properties between HRQOL questionnaires. The internal consistency was good for all questionnaires; the Cronbach's $\alpha$ coefficient was highest for LCQ. The test-retest reliability was high for the LCQ and SGRQ domains and variable for the QOL-B domain, ranging from moderate to good. The 
Table 3 Meta-analysis: correlations reported for health-related quality of life with clinical measures

\begin{tabular}{|c|c|c|c|c|c|c|}
\hline Clinical measures & K & $\mathbf{N}$ & Meta-analysis correlation mean $\mathrm{r}(95 \% \mathrm{Cl})$ & Q test & $I^{2}(\%)$ & Rosenthal's N \\
\hline Cough & 2 & 124 & $0.57(-0.03$ to 0.87$) ; p=0.060$ & $7.56 ; p=0.006$ & $86.8^{*}$ & $20+$ \\
\hline Dyspnoea & 7 & 1216 & 0.55 (0.41 to 0.68$) ; p<0.001$ & $54.42 ; p<0.001$ & $89.0^{*}$ & 792 \\
\hline Wheeze & 2 & 213 & $0.42(0.30$ to 0.53$) ; p<0.001$ & $0.27 ; p=0.602$ & 0.0 & 29 \\
\hline Fatigue & 4 & 182 & $0.42(0.23$ to 0.58$) ; p<0.001$ & $4.72 ; p=0.194$ & 36.4 & 40 \\
\hline Exercise capacity & 11 & 1038 & $-0.41(-0.54$ to -0.24$) ; p<0.001$ & $50.81 ; p<0.001$ & $80.3^{*}$ & 419 \\
\hline Depression & 7 & 572 & 0.41 (0.23 to 0.55$) ; p<0.001$ & $27.53 ; p<0.001$ & $78.2^{*}$ & 220 \\
\hline Sputum volume & 3 & 402 & $0.36(0.24$ to 0.47$) ; p<0.001$ & $3.39 ; p=0.184$ & 41.0 & 57 \\
\hline Pseudomonas presence/colonisation & 2 & 189 & $0.36(0.23$ to 0.48$) ; p<0.001$ & $0.70 ; p=0.401$ & 0.0 & $18 t$ \\
\hline CT bronchiectasis scores & 9 & 1338 & $0.35(0.03$ to 0.61$) ; p<0.001$ & $253.63 ; p<0.001$ & $96.8^{*}$ & 856 \\
\hline Oxygen saturation & 4 & 324 & $-0.35(-0.44$ to -0.24$) ; p<0.001$ & $0.46 ; p=0.928$ & 0.0 & 51 \\
\hline Anxiety & 5 & 514 & $0.34(0.19$ to 0.47$) ; p=0.025$ & $11.38 ; p=0.023$ & $64.9 \neq$ & 97 \\
\hline Hospital admissions rate & 2 & 695 & $0.34(0.16$ to 0.49$) ; p<0.001$ & $2.95 ; p=0.086$ & $66.1 \neq$ & 55 \\
\hline $\mathrm{FEV}_{1} \%$ & 17 & 2228 & $-0.31(-0.40$ to -0.23$) ; p<0.001$ & $59.32 ; p=0.000$ & $73.0 \ddagger$ & 990 \\
\hline Infections/exacerbations rate & 8 & 1498 & 0.31 (0.24 to 0.38$) ; p=0.001$ & $12.99 ; p=0.072$ & 46.1 & 380 \\
\hline FVC $\%$ & 7 & 1031 & $-0.30(-0.41$ to -0.19$) ; p<0.001$ & $14.39 ; p=0.026$ & $58.3 \ddagger$ & 182 \\
\hline Any microbiological presence/colonisation & 3 & 758 & 0.26 (0.19 to 0.33$) ; p<0.001$ & $0.43 ; p=0.805$ & 0.0 & 43 \\
\hline Sputum colour & 2 & 204 & 0.25 (0.05 to 0.43$) ; p=0.013$ & $1.91 ; p=0.167$ & 47.6 & $7 \dagger$ \\
\hline Comorbidities & 2 & 815 & $0.09(0.02$ to 0.16$) ; p=0.014$ & $0.44 ; p=0.508$ & 0.0 & $3+$ \\
\hline \multicolumn{7}{|c|}{$\begin{array}{l}\text { For the purposes of comparison, higher score indicates poorer health-related quality of life. } \\
\text { Statistical heterogeneity among the studies was assessed using the } Q \text { test and quantified using the } \mathrm{I}^{2} \text {. } \\
\mathrm{I}^{2} \text {, Indicates the percentage of total variation across studies that is due to heterogeneity rather than chance. } \mathrm{I}^{2} \text { value of } 0 \% \text { was considered to indicate no observed heterogeneity. } \\
{ }^{*} \mathrm{I}^{2} \text { between } 75-100 \% \text { may represent considerable heterogeneity. } \\
+ \text { Rosenthal's Number lower than } 5 \times k_{\text {number of studies }}+10 \text { indicates publication bias of the studies included in the meta-analysis. } \\
\mp \mathrm{I}^{2} \text { between } 30-60 \% \text { may represent moderate heterogeneity among the studies according to Cochrane manual. } \\
\mathrm{K} \text {, number of studies; } \mathrm{N} \text {, number of overall participants; } \mathrm{Q} \text {, Cochran's } \mathrm{Q} \text { test, which examines the null hypothesis that all studies are evaluating the same effect; } r \text {, correlation coefficient. }\end{array}$} \\
\hline
\end{tabular}

convergent validity was also variable for the clinical measures studied. The association with exercise capacity was marginally better with the SGRQ and LCQ questionnaires compared with
QOL-B. The association between HRQOL with $\mathrm{FEV}_{1}$ was generally weak, irrespective of the questionnaire administered. The association with symptoms of dyspnoea was stronger with

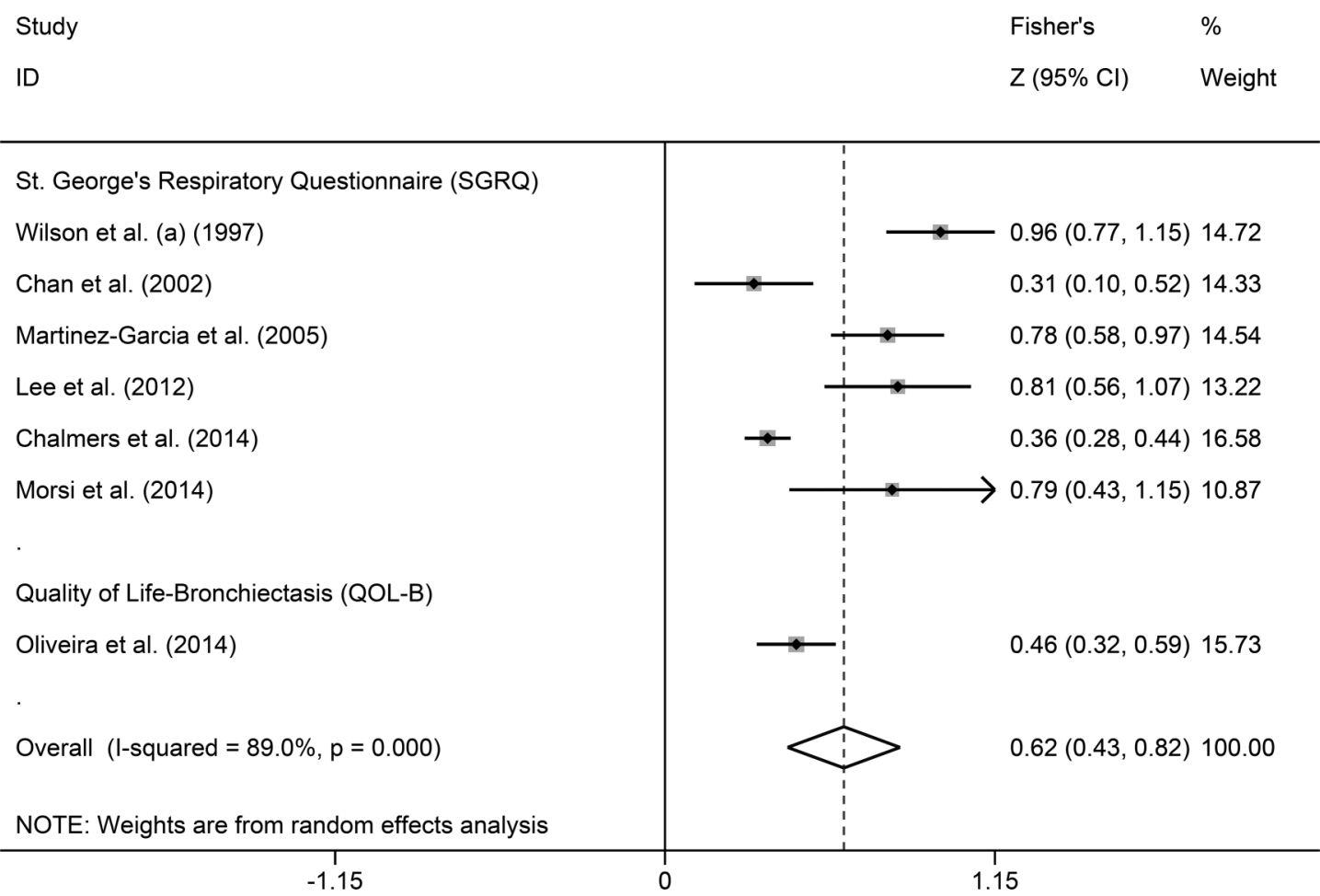

Figure 3 Forest plot for the correlation between health-related quality of life and dyspnoea. Measurements of dyspnoea used: Medical Research Council (MRC) scale (Wilson et al, 1997; Martinez-Garcia et al, 2005; Lee et al, 2012; Chalmers et al, 2014; Oliveira et al, 2014), 12-point Borg scale (Chan et al, 2002) and dyspnoea-12 (Morsi et al, 2014). Zero line: is illustrated to indicate the direction of association. A fisher's $z$ value $>0$ indicates positive association between the two variables. A fisher's $z$ value $<0$ indicates negative association between the two variables. High score = poor health-related quality of life. Dashed line: represents the overall meta-analytic mean Z. Arrow: indicates confidence interval limit. Weight was calculated using the inverse variance weight formula [weight=i/sqrt(n-3)]. 


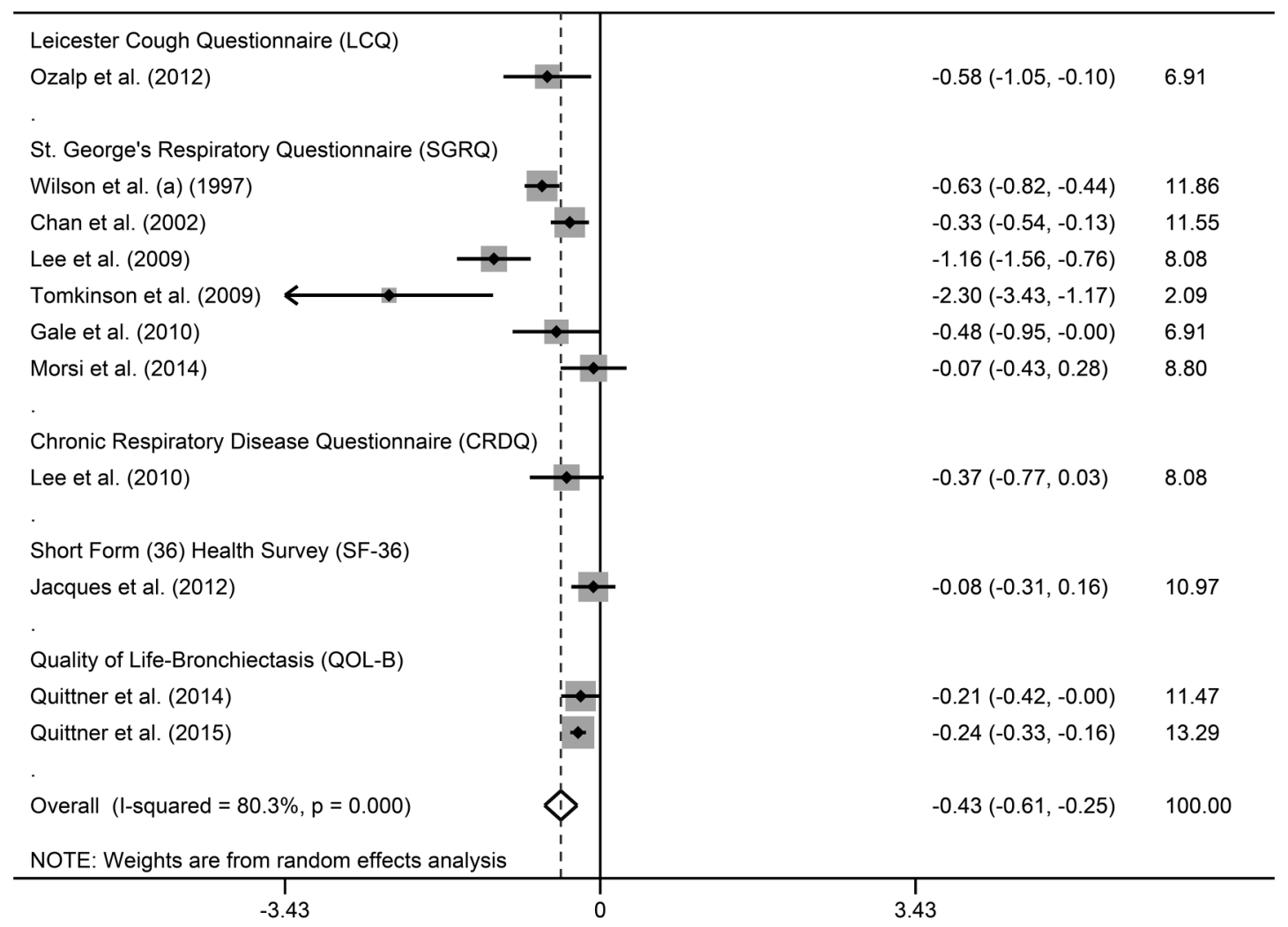

Figure 4 Forest plot for the correlation between health-related quality of life and exercise capacity. Measurements of exercise capacity used: 6 minute walk test for all studies apart from one that used incremental shuttle walk test (Wilson et al, 1997) and another that used both (Lee et al, 2010). High score $=$ poor health-related quality of life.

SGRQ compared with QOL-B. It is possible that the differences identified in the psychometric properties of questionnaires may reflect differences in the study population, disease characteristics and study methods. Studies that directly compare HRQOL questionnaires are needed to establish similarities and differences between questionnaires with greater confidence.

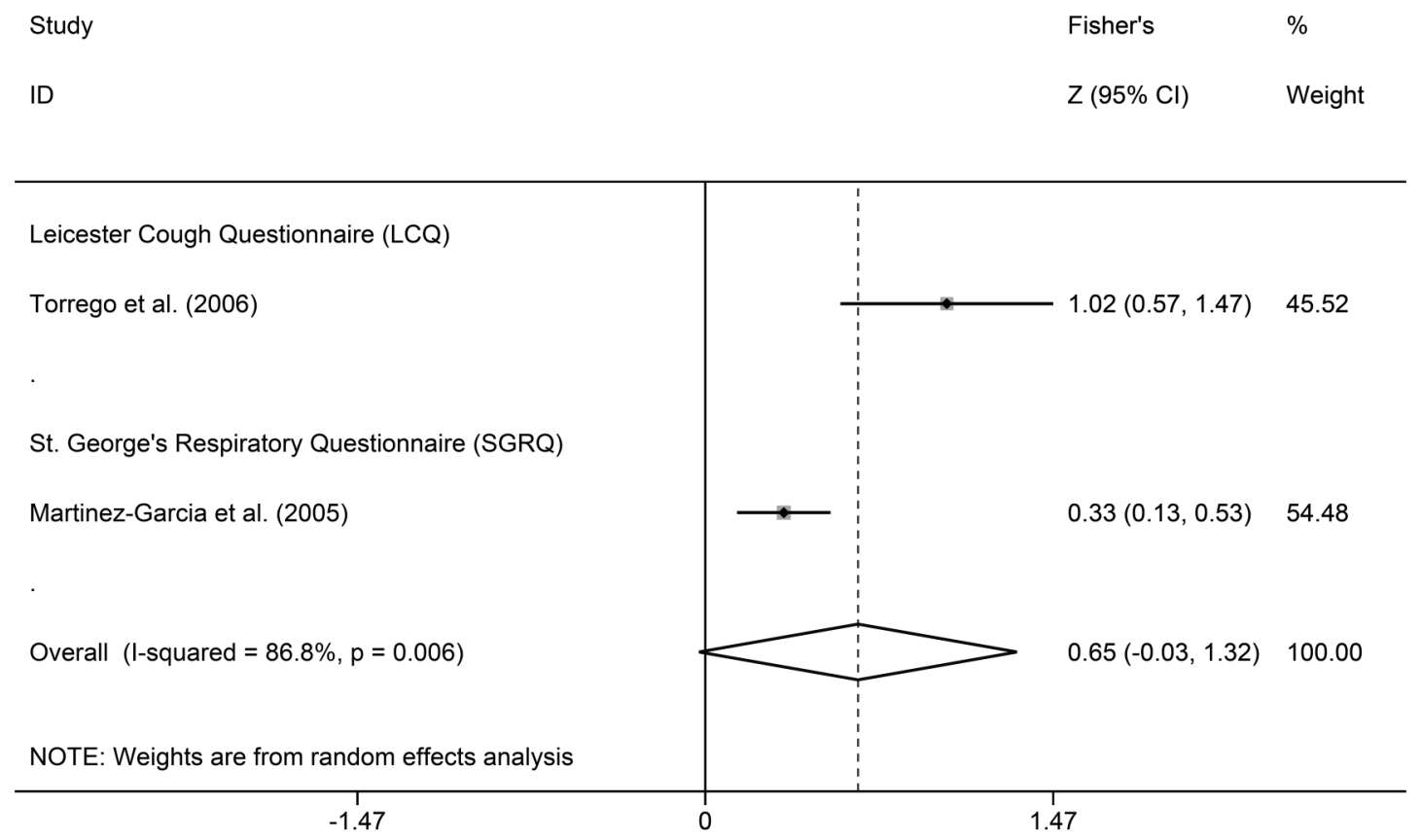

Figure 5 Forest plot for the correlation between health-related quality of life and cough. Measurements of cough used: cough reflex sensitivity to capsaicin (Torrego et al, 2006) and patient-reported cough frequency (Martinez-Garcia et al, 2005). High score = poor health-related quality of life. 


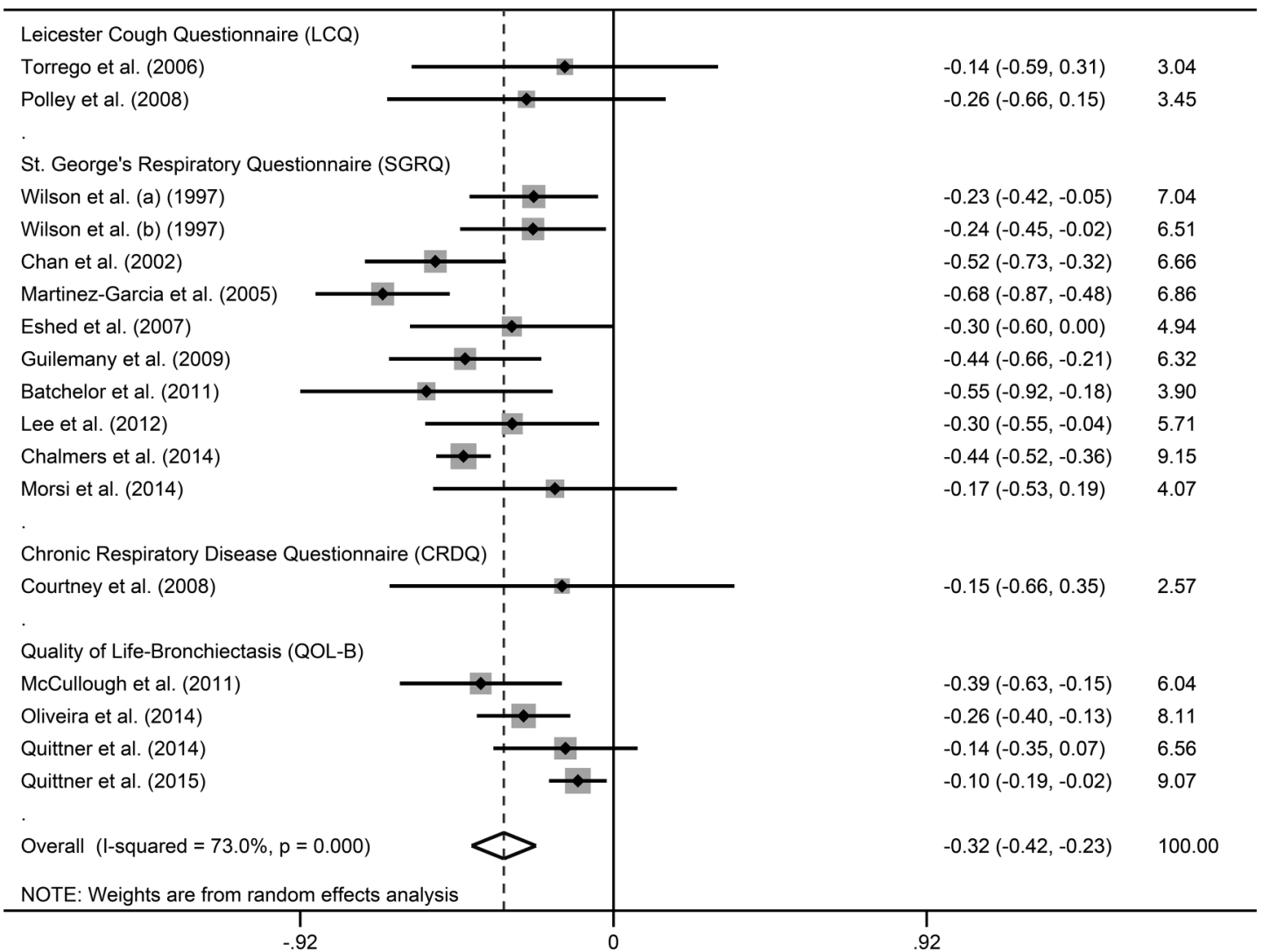

Figure 6 Forest plot for the correlation between health-related quality of life and $\mathrm{FEV}_{1} \%$ predicted. High score $=$ poor health-related quality of life.

The responsiveness, MCID and translation validity of HRQOL questionnaires were also investigated. Based on randomised controlled trials, SRMs were variable. The MCID has only been reported for one HRQOL questionnaire in patients with bronchiectasis (QOL-B); ${ }^{33}$ further studies are needed to establish MCID of other widely used questionnaires. Many studies used translated HRQOL questionnaires. While there were good examples of translated HRQOL questionnaire validity in bronchiectasis, there were many studies where this procedure was either not conducted or reported. It is essential that HRQOL questionnaires are translated and validated using well recognised and standardised procedures to ensure that they are appropriately adapted to accommodate cultural differences. ${ }^{38}$

The assessment of convergent validity demonstrated a stronger relationship of HRQOL with subjective outcome measures compared with objective measures. The strongest association of HRQOL was with respiratory symptoms. The review also highlights a potentially important association between HRQOL and fatigue. Fatigue is a recognised symptom of bronchiectasis but its mechanism is poorly understood. ${ }^{27}$ There was a poor association between HRQOL and frequency of acute exacerbations. This may be because most studies assessed HRQOL during a clinically stable phase. The best identified association among objective measures was with exercise capacity, such as the 6-min walk test. This is not surprising, since exercise capacity is more likely to relate to functional ability than other objective outcome measures. Our findings highlight the discordance between patient-reported outcome measures and physiological measures, such as $\mathrm{FEV}_{1}$, and are consistent with findings for other chronic respiratory disorders, such as COPD. ${ }^{39}$ This suggests that HRQOL questionnaires assess a unique dimension of health, which is distinct from that assessed by objective measures. HRQOL measures should ideally complement objective clinical measures in the assessment of bronchiectasis.

There are some limitations with our systematic review. Our review is susceptible to publication bias (positive findings are more likely to be published compared with negative findings) and time lag bias (inability to identify ongoing or unpublished studies), as any review article. We did not contact the study authors to retrieve unpublished data, which may lead to overinterpretation of associations between HRQOL and clinical measures; this applies particularly to studies published in abstract form. We chose to limit the review to those studies specifically evaluating the psychometric properties of HRQOL questionnaires and associations with clinical measures. For the purpose of analysis, we grouped clinical measures together. We therefore may have underestimated important associations due to the heterogeneity of clinical outcome measures. We used the average of HRQOL domain scores when total scores were not reported. Other potential sources for heterogeneity were differences in inclusion/exclusion criteria, population and disease aetiology. The quality of HRQOL data and its reporting varied between studies. We assessed the quality of studies with a modified version of a tool developed by Swigris et $a l^{1}$ as this was the most comprehensive and relevant for our purpose. The included studies met an average $48 \%$ of the quality criteria assessed, 
which is similar to a systematic review of HRQOL in idiopathic pulmonary fibrosis. ${ }^{1}$ A greater proportion of studies met the quality criteria relating to description of patient demographics, the reporting of major clinical outcome measures of bronchiectasis and the analysis of HRQOL data. Fewer studies met the criteria for reporting details of the administration of the HRQOL questionnaires, floor/ceiling effects and missing data. It is therefore possible that the quality of studies and data-reporting may have compromised some of our findings. A greater clarity for HRQOL data-reporting is required in future studies including reporting of the rationale for choosing a particular instrument, mode of administration, details of missing data and sample size estimates. The questionnaires identified in this review have been in use for variable lengths of time. It is likely that this may have impacted on the availability of evidence.

Our review highlights the questionnaire options available. SGRQ is a good choice for a research study if extensive experience of use of an HRQOL questionnaire is important. SGRQ also has good psychometric validity and the strongest association with dyspnoea. Its disadvantage is that it is a long questionnaire and potentially may not be as responsive to change as disease-specific tools; this requires further study. LCQ is brief, well validated in bronchiectasis and may be particularly advantageous if cough is the symptom of primary focus. QOL-B is the only disease-specific questionnaire and has good psychometric properties. The disadvantage of QOL-B is that it is relatively long and does not have a total score that would simplify interpretation of data. SF-36 may be useful in comparative studies that include non-pulmonary disorders, as it is a generic tool. It is however a relatively long questionnaire and is not as extensively validated in bronchiectasis as some of the alternatives. There is a need for briefer tools with simplified scoring (ideally inclusive of a total score) for use in the clinical and research settings. The bronchiectasis severity index is one such example, although not a measure of HRQOL. ${ }^{35}$

In conclusion, HRQOL questionnaires used in bronchiectasis have generally good psychometric properties. There are some differences between questionnaires in their association with clinical measures. Investigators should select questionnaires for their study based on the ease of administration and the questionnaire's correlation with the primary health domain under investigation. More research is needed to investigate longitudinal changes in HRQOL and establish MCID of instruments.

\section{Author affiliations \\ ${ }^{1}$ Division of Asthma, Allergy and Lung Biology, King's College London, Respiratory Medicine, London, UK \\ ${ }^{2}$ Division of Medicine, University College London (UCL), London, UK \\ ${ }^{3}$ Adult Cystic Fibrosis Unit, King's College Hospital, London, UK \\ ${ }^{4}$ Auckland University of Technology (AUT), School of Public Health and Psychosocial Studies and School of Rehabilitation and Occupation Studies, Auckland, New Zealand \\ ${ }^{5}$ Host Defence Unit, Royal Brompton Hospital, London, UK \\ ${ }^{6}$ Denmark Hill Campus, King's College London, Therapies, London, UK}

Twitter Follow Konstantinos Fragkos at @costasfrangos

Acknowledgements The authors thank Mr A Drongitis for his assistance in screening papers for inclusion.

Contributors Conception: AS, RG, SSB; Study design: all authors; Data collection: AS, KCF; Analysis and interpretation: all authors; Writing of the manuscript: AS, SSB; Revision and approval of the manuscript: all authors.

Competing interests None of the authors has a financial relationship with a commercial entity that has an interest in the subject of this manuscript. AS is completing a PhD that was financially supported by Greek State Scholarships Foundation (IKY). SSB is a developer of HRQOL tools. RW and MRL were co-authors of studies included in the review.
Provenance and peer review Not commissioned; externally peer reviewed.

\section{REFERENCES}

1 Swigris JJ, Kuschner WG, Jacobs SS, et al. Health-related quality of life in patients with idiopathic pulmonary fibrosis: a systematic review. Thorax 2005;60:588-94.

2 Pasteur MC, Bilton D and Hill AT. British Thoracic Society guideline for non-CF bronchiectasis. Thorax 2010;65(Suppl 1):i1-58.

3 Martínez-Garcia MA, Perpiñá-Tordera M, Román-Sánchez P, et al. Quality-of-life determinants in patients with clinically stable bronchiectasis. Chest 2005a;128: 739-45.

4 Jacques PS, Gazzana MB, Palombini DV, et al. Six-minute walk distance is not related to quality of life in patients with non-cystic fibrosis bronchiectasis. $J$ Bras Pneumol 2012:38:346-55.

5 Wilson CB, Jones PW, O'Leary CJ, et al. Validation of the St. George's Respiratory Questionnaire in bronchiectasis. Am J Respir Crit Care Med 1997;156(2 Pt 1):536-41.

6 Quittner AL, Marciel KK, Salathe MA, et al. A preliminary quality of life questionnaire-bronchiectasis: a patient-reported outcome measure for bronchiectasis. Chest 2014;146:437-48.

7 Murray MP, Turnbull K, MacQuarrie S, et al. Validation of the Leicester Cough Questionnaire in non-cystic fibrosis bronchiectasis. Eur Respir J 2009a;34:125-31.

8 Group PRISMA. The PRISMA statement. http://www.prisma-statement.org/ (accessed 8 Apr 2014).

9 Scottish Intercollegiate Guidelines Network. SIGN methodology checklist 1: systematic reviews and meta-analyses. http://www.sign.ac.uk/methodology/ checklists.html (accessed 8 Apr 2014).

10 Rosenthal R, Rosnow R, Land Rubin DB. Contrasts and effect sizes in behavioral research: a correlational approach. Cambridge: Cambridge University Press, 2000.

11 Higgins J, Deeks J. Selecting studies and collecting data. In: Higgins J, Green S, eds Cochrane handbook for systematic reviews of interventions version 5.1.0 (updated March 2011). The Cochrane Collaboration, 2011. http://handbook.cochrane.org/ (accessed 8 Apr 2014).

12 Fragkos KC, Tsagris M, Frangos CC. Publication bias in meta-analysis: confidence intervals for Rosenthal's fail-safe number. Int Scholarly Res Notices 2014;2014 (Article ID 825383):1-17.

13 Quittner AL, Cruz I, Marciel KK, et al. Development and cognitive testing of the Quality of Life Questionnaire for Bronchiectasis (QOL-B). Am J Respir Crit Care Med 2010;179:A4310 (Abstract).

14 Munoz G, Olveira C, Martinez-Garcia MA, et al. Validation of a Spanish version of the Leicester Cough Questionnaire in adult patients with non-cystic fibrosis bronchiectasis. Eur Respir J 2013:42(Suppl 57):P5068 (Abstract).

15 Tomkinson JL, Bruton A. The 6-minute walk test for patients with bronchiectasis: comparison with normal predictive data. Journal of the Association of Chartered Physiotherapists in Respiratory Care 2009;41:16-21.

16 Loebinger MR, Wells AU, Hansell DM, et al. Mortality in bronchiectasis: a long-term study assessing the factors influencing survival. Eur Respir J 2009;34:843-9.

17 Chan SL, Chan-Yeung MM, Ooi GC, et al. Validation of the Hong Kong Chinese version of the St. George Respiratory Questionnaire in patients with bronchiectasis. Chest 2002;122:2030-7

18 Girón Moreno RM, Fernandes Vasconcelos G, Cisneros C, et al. Presence of anxiety and depression in patients with bronchiectasis unrelated to cystic fibrosis. Arch Bronconeumol 2013:49:415-20 (Abstract).

19 Murray MP, Twiss J, McKenna SP, et al. The utility of the nottingham health profile in exacerbations of non-cystic fibrosis bronchiectasis. Thorax 2010;65:A176 (Abstract).

20 Quittner AL, Salathe M, Gotfried M, et al. National validation of a patient-reported outcome measure for bronchiectasis: psychometric results on the QOL-B. Am J Respir Crit Care Med 2010;181:A5793 (Abstract).

21 Olveira C, Olveira G, Espildora F, et al. Validation of a quality of life questionnaire for bronchiectasis: psychometric analyses of the Spanish QOL-B-V3.0. Qual Life Res 2014;23:1279-92.

22 Murray MP, Turnbull K, Macquarrie $S$, et al. Assessing response to treatment of exacerbations of bronchiectasis in adults. Eur Respir J 2009;33:312-18.

23 Courtney JM, Kelly MG, Watt A, et al. Quality of life and inflammation in exacerbations of bronchiectasis. Chron Respir Dis 2008;5:161-8.

24 Altenburg J, Wortel K, de Graaff CS, et al. Validation of a visual analogue score (LRTI-VAS) in non-CF bronchiectasis. Clin Respir J 2016;10:168-75.

25 Lee $\mathrm{AL}$, Cecins N, Hill CJ, et al. Utility of the chronic respiratory questionnaire in non-cystic fibrosis (CF) bronchiectasis. Respirology 2010;15:A78 (Abstract).

26 Morsi TS, Ghobashy S, Younis G. Quality of life and psychological disorders in Egyptian patients with chronic lung diseases: clinico-physiological correlation. Egypt J Chest Dis Tuberc 2014;63:731-42.

27 Ozalp 0 , Inal-Ince D, Calik E, et al. Extrapulmonary features of bronchiectasis: muscle function, exercise capacity, fatigue, and health status. Multidiscip Respir Med 2012;7:3.

28 Polley L, Yaman N, Heaney L, et al. Impact of cough across different chronic respiratory diseases: comparison of two cough-specific health-related quality of life questionnaires. Chest 2008;134:295-302.

29 Torrego A, Haque RA, Nguyen LT, et al. Capsaicin cough sensitivity in bronchiectasis. Thorax 2006;61:706-9. 
30 Martinez Garcia MA, Perpina Tordera M, Roman Sanchez P, et al. Internal consistency and validity of the Spanish version of the St. George's respiratory questionnaire for use in patients with clinically stable bronchiectasis. Arch Bronconeumol 2005b;41:110-17.

31 Guilemany JM, Alobid I, Angrill J, et al. The impact of bronchiectasis associated to sinonasal disease on quality of life. Respir Med 2006;100:1997-2003.

32 Lee BY, Lee S, Lee JS, et al. Validity and reliability of CAT and Dyspnea-12 in Bronchiectasis and Tuberculous destroyed lung. Tuberc Respir Dis (Seoul) 2012;72:467-74.

33 Quittner AL, O'Donnell AE, Salathe MA, et al. Quality of life questionnaire-bronchiectasis: final psychometric analyses and determination of minimal important difference scores. Thorax 2015;70:12-20.

34 Wilson CB, Jones PW, O'Leary CJ, et al. Effect of sputum bacteriology on the quality of life of patients with bronchiectasis. Eur Respir J 1997b;10:1754-60.

35 Chalmers JD, Goeminne P, Aliberti S, et al. The bronchiectasis severity index. An international derivation and validation study. Am J Respir Crit Care Med 2014;189:576-85.
36 Food and Drug Association (FDA). Guidance for industry. Patient-reported outcome measures: use in medical product development to support labeling claims. In: Services USDoHaH, Administration FaD, (CDER) CfDEaR, et al., eds. 2009:1-39 http://www.fda.gov/downloads/Drugs/.../Guidances/UCM193282.pdf (accessed 8 Apr 2014)

37 Barker $A F$, O'Donnell $A E$, Flume $P$, et al. Aztreonam for inhalation solution in patients with non-cystic fibrosis bronchiectasis (AIR-BX1 and AIR-BX2): two randomised double-blind, placebo-controlled phase 3 trials. Lancet Respir Med 2014;2:738-49.

38 Wild D, Grove A, Martin M, et al. Principles of good practice for the translation and cultural adaptation process for Patient-Reported Outcomes (PRO) measures: report of the ISPOR task force for translation and cultural adaptation. Value Health 2005; 8:94-104. .

39 Ketelaars CA, Schlösser MA, Mostert R, et al. Determinants of health-related quality of life in patients with chronic obstructive pulmonary disease. Thorax 1996;51:39-43. 